OCCASIONAL REVIEW

\title{
The need for standardisation of peak flow charts
}

\author{
H K Reddel, S D Vincent, J Civitico
}

Thorax 2005;60:164-167. doi: 10.1136/thx.2004.030437

Peak expiratory flow (PEF) monitoring is recommended in asthma guidelines as a tool for assessing severity, monitoring response to treatment, detecting exacerbations, identifying triggers, and providing objective justification for treatment to the patient, but some clinicians have expressed concerns about its relevance in the management of asthma. We have identified a sevenfold variation in the scale of existing PEF charts, with resulting wide variation in the appearance of the same PEF date on different charts. There is an obvious need for standardisation of PEF charts to avoid confusion for patients and to allow development of pattern recognition skills by clinicians. Evidence is provided from visual perception studies to suggest that preference should be given to a horizontally compressed PEF chart to facilitate identification of exacerbations and of overall trends, but this needs to be formally evaluated by retrospective and prospective studies. It is hoped that clinical expertise in PEF pattern recognition can eventually be incorporated into electronic decision making algorithms, as has occurred in occupational asthma, but, in the meantime, the ideal PEF chart for asthma management will represent a compromise between ease of manual data entry and ease of interpretation.

See end of article for authors' affiliations

Correspondence to Correspondence to:
Dr H Reddel, Woolcock Institute of Medical Research (RPAH and University of Sydney), P O Box M77, Camperdown, NSW 2050, Australia: hkr@woolcock.org.au

Received 20 June 2004 Accepted 30 August 2004
$\mathrm{P}$ eak expiratory flow (PEF) monitoring is recommended in asthma guidelines as a tool for assessing severity, monitoring response to treatment, detecting exacerbations, identifying triggers, and providing objective justification for treatment to the patient. ${ }^{1}$ The incorporation of PEF based action plans into coordinated selfmanagement education programmes has been shown to improve health outcomes. ${ }^{2}$ However, despite these recommendations, there are few practical resources available for interpretation of PEF data in clinical practice.

\section{EXISTING TOOLS FOR INTERPRETATION OF PEAK FLOW DATA}

In a routine consultation a clinician will not usually have access to computerised processing of PEF data, so the conventional PEF outcomes used in clinical trials to assess change in status (such as mean morning PEF or diurnal variability) are not practicable. For PEF based action plans the clinician nominates a threshold PEF value which represents a significant change from the patient's usual status, at which the patient is advised to change his/her treatment. Guideline recommendations for calculation of these action points are, for simplicity, based on percentage calculations from predicted or personal best PEF. $^{2}$ The sensitivity and specificity of such percentage criteria in identifying exacerbations is poor compared with that of standard deviation criteria, as the latter take into account the patient's previous level of PEF variability. ${ }^{3}$ However, standard deviation calculations require computerised entry and analysis. Boggs and colleagues $^{4}$ have used statistical process control charts for display of PEF data but, once again, this process requires computerised processing.

The visual recognition of patterns of airflow obstruction was described by Turner-Warwick in $1977,{ }^{5}$ shortly after the introduction of portable PEF meters. Mitchell and colleagues later validated inspection of PEF charts for the identification of treatment response in chronic airflow limitation. ${ }^{6}$ The most striking example of the use of visual inspection of PEF charts has been in the field of occupational asthma. In a series of seminal articles published in Thorax, the use of PEF monitoring in the diagnosis of occupation asthma was described in 1979 by Burge and colleagues, ${ }^{7}$ with subsequent validation of expert visual interpretation of PEF charts against specific challenges ${ }^{89}$ and eventual incorporation of these processes into a computerised diagnostic algorithm (OASYS). ${ }^{10}$

\section{HUMAN VISUAL PERCEPTION AND PATTERN RECOGNITION SKILLS}

The use of a chart or graph is regarded as the most efficient way to detect outlying or abnormal values in a series dataset. ${ }^{11}$ Visual assessment of PEF charts might appear to be very "soft" science. However, in visual perception literature it is axiomatic that human visual pattern recognition processes are highly sophisticated and reliable. In a recent review, Grill-Spector stated that "One of the greatest mysteries in cognitive science is the human ability to recognize visuallypresented objects with high accuracy and lightning speed. Interest in how human object recognition works is heightened by the fact that efforts to duplicate this ability in machines have not met with extraordinary success $^{\prime \prime}{ }^{12}$ This perspective is highlighted by the retention of visual displays in environments (both medical and non-medical) which require rapid decisions. For example, intensive care units still display electrocardiogram traces for instantaneous diagnosis of arrhythmias such as ventricular tachycardia, despite the availability of complex computerised analysis.

It has long been accepted that the format of a visual display affects the way in which graphed data are interpreted..$^{13}$ For example, the usefulness of electrocardiogram traces is completely dependent on universal standardisation of the 
recording scale; and we would quickly abandon analogue clocks if the "12" was orientated randomly around the dial. In the field of occupational asthma, standardisation of PEF charts was implemented at an early stage in recognition of its importance in the facilitation of expert pattern recognition. ${ }^{9}$

\section{HOW MUCH VARIATION EXISTS BETWEEN PEF CHARTS AT PRESENT?}

Asthma guidelines, while recommending PEF monitoring, do not specify a particular format for recording PEF. We have been able to obtain 17 different full range (>500 l/min) PEF charts (table 1): eight packaged with PEF meters, four distributed by pharmaceutical companies, two published as online supplements to asthma guidelines (Global Initiative for Asthma (GINA) website; ${ }^{14}$ British asthma guideline (BTS/ SIGN) website ${ }^{15}$ which reproduces the Asthma UK brochure "Your Personal Asthma Diary and Action Plan"16), a l year booklet (FP1010) available from the UK National Health Service, a prototype chart from our asthma clinic, and an OASYS chart designed for computerised plotting. ${ }^{9}$

There was considerable variation between the charts (table 1 ) in the range of PEF values which could be plotted, the number of measurements per day, and the number of days' data per page, the latter ranging from 4 days (GINA) to 57 days (Asthma Daily Record Card). Because of these variations, differences in the scale of the charts were not immediately obvious. Chart scale, calculated as the ratio of standardised vertical height to horizontal width, ranged from 100:825 for the GINA chart to 100:119 for the Asthma UK chart. This represents an almost sevenfold difference in scale between the two guideline charts. The scale rose to 100:82 on the prototype chart and 100:39 on the occupational asthma chart.

\section{EFFECT OF VARIATION IN CHART FORMAT ON THE INTERPRETATION OF PEF DATA}

The effect of chart scale on the appearance of PEF data can be seen by plotting a sample exacerbation on each chart. Figure 1 shows a severe exacerbation experienced by a 49 year old woman during a viral respiratory infection on a background of good asthma control, ${ }^{17}$ with PEF recorded from twice daily electronic spirometry on a MicroMedical DiaryCard spirometer. Peak flow fell by 31\% (156 l/min, 8.3 standard deviations) below baseline over 4 days, then recovered over a further 6 days. For each chart the angle of onset of the exacerbation (mean slope over days 1-4) was reported as degrees from the horizontal. This angle ranged from $10^{\circ}$ (GINA) to $52^{\circ}$ (Asthma UK), increasing to $62^{\circ}$ on the prototype chart and $75^{\circ}$ on the occupational asthma chart (table 1). The resulting variation in the qualitative appearance of the sample exacerbation was striking. On horizontally expanded charts (fig $1 \mathrm{~A}$ and $\mathrm{B}$ ) the exacerbation onset and resolution were difficult to identify, but on horizontally compressed charts (fig IC and D) the exacerbation stood out abruptly from adjacent data.

The implications of this variation in scale are obvious. Clinicians who repeatedly view PEF charts at patient visits should be able to develop clinical pattern recognition skills in the interpretation of PEF data. ${ }^{5}$ However, if similar episodes may have a markedly different appearance according to which PEF chart was used, there is no opportunity for these skills to develop. In addition, if a whole exacerbation episode (steady state-deterioration-recovery-steady state) cannot be readily identified retrospectively on a particular chart format, then prospective detection of an evolving exacerbation on the same chart would be extremely difficult. It is relevant to note that highly compressed displays were used to demonstrate the temporal associations between viral infections and asthma exacerbations, ${ }^{18}$ and to identify the differences between the V-shaped PEF changes of viral exacerbations and the chaotic PEF variation of uncontrolled asthma. ${ }^{17} \mathrm{~A}$ highly compressed chart appears to have been used in validating visual inspection of treatment response in COPD. ${ }^{6}$

The number of weeks of data which can be recorded on each chart page is also likely to have an impact on the interpretation of PEF data. The scale calculations in table 1 assumed a continuous record of 31 days but, in practice, charts displaying only a few days per page (e.g. GINA, AsthmaCare, UK Government booklet) would be difficult to interpret because of breaks in continuity between pages. Given the known time course of the response to inhaled corticosteroids and of exacerbations, long term PEF data,

Table 1 Characteristics of charts available for measuring peak expiratory flow (PEF)

\begin{tabular}{|c|c|c|c|c|c|}
\hline Chart & Source & $\begin{array}{l}\text { No of days of } \\
\text { data per page }\end{array}$ & $\begin{array}{l}\text { Range of PEF values } \\
\text { (min-max, } 1 / \mathrm{min} \text { ) }\end{array}$ & Scale* & $\begin{array}{l}\text { Angle of onset of } \\
\text { exacerbation } t\end{array}$ \\
\hline Global Initiative for Asthma & Guidelines website $^{14}$ & 4 & $60-800$ & $100: 825$ & $10^{\circ}$ \\
\hline Allersearch & Packaged with PEF meter & 23 & $50-700$ & $100: 382$ & $22^{\circ}$ \\
\hline AsthmaCare & Pharmaceutical company & 14 & $0-1000 \ddagger$ & $100: 345$ & $24^{\circ}$ \\
\hline MicroPeak & Packaged with PEF meter & 28 & $100-800$ & $100: 334$ & $24^{\circ}$ \\
\hline FDE & Packaged with PEF meter & 14 & $0-700$ & $100: 324$ & $25^{\circ}$ \\
\hline Breath Alert & Packaged with PEF meter & 22 & $100-700$ & $100: 268$ & $29^{\circ}$ \\
\hline Assess & Packaged with PEF meter & 14 & $50-900$ & $100: 251$ & $31^{\circ}$ \\
\hline Asthma Daily Record Card & Pharmaceutical company & 57 & $0-1000 \ddagger$ & $100: 246$ & $32^{\circ}$ \\
\hline Personal best & Packaged with PEF meter & 28 & $50-900$ & $100: 237$ & $33^{\circ}$ \\
\hline Allen \& Hanburys & Pharmaceutical company & 42 & $50-650$ & $100: 232$ & $33^{\circ}$ \\
\hline MiniWright & Packaged with PEF meter & 42 & $0-700$ & $100: 230$ & $33^{\circ}$ \\
\hline Peak flow meter charts (FP1010) & UK NHS & $14 \S$ & $0-700$ & $100: 221$ & $34^{\circ}$ \\
\hline Big Bright Blue Breathing Book & Pharmaceutical company & 31 & $0-650$ & $100: 174$ & $41^{\circ}$ \\
\hline Airzone & Packaged with PEF meter & 32 & $100-700$ & $100: 157$ & $44^{\circ}$ \\
\hline $\begin{array}{l}\text { Your Personal Asthma Diary and } \\
\text { Action Plan }\end{array}$ & $\begin{array}{l}\text { Asthma UK, }{ }^{16} \text { reproduced on } \\
\text { British guideline website }\end{array}$ & 28 & $100-700$ & $100: 119$ & $52^{\circ}$ \\
\hline Prototype chart & $\begin{array}{l}\text { Woolcock Institute of Medical } \\
\text { Research }\end{array}$ & 56 & $0-750$ & $100: 82$ & $62^{\circ}$ \\
\hline Occupational asthma format & Bright and Burge 9 & $\mathrm{~N} / \mathrm{A} \cdot$ & $\mathrm{N} / \mathrm{A} \cdot$ & $100: 39$ & $76^{\circ}$ \\
\hline
\end{tabular}

*Scale was calculated as the ratio of vertical height to horizontal width. The vertical height was standardised such that $100 \mathrm{~mm}$ represented a range of $0-800$ $\mathrm{I} / \mathrm{min}$, then the horizontal width was calculated for a period of 31 days.

†Angle formed by the first 4 days of the sample exacerbation in degrees from the horizontal.

$\ddagger$ Axis unlabelled but 10 major divisions on vertical axis, so analysed as $0-1000 \mathrm{l} / \mathrm{min}$ for full range chart.

$\S$ This booklet contains sufficient 2 week charts for 1 year of monitoring.

This chart format is designed for computerised entry of multiple daily PEF values. A limited PEF range relevant to the individual patient is displayed, with 20

$\mathrm{I} / \mathrm{min}=10 \mathrm{~mm}$ and 1 day $=5 \mathrm{~mm}$. 

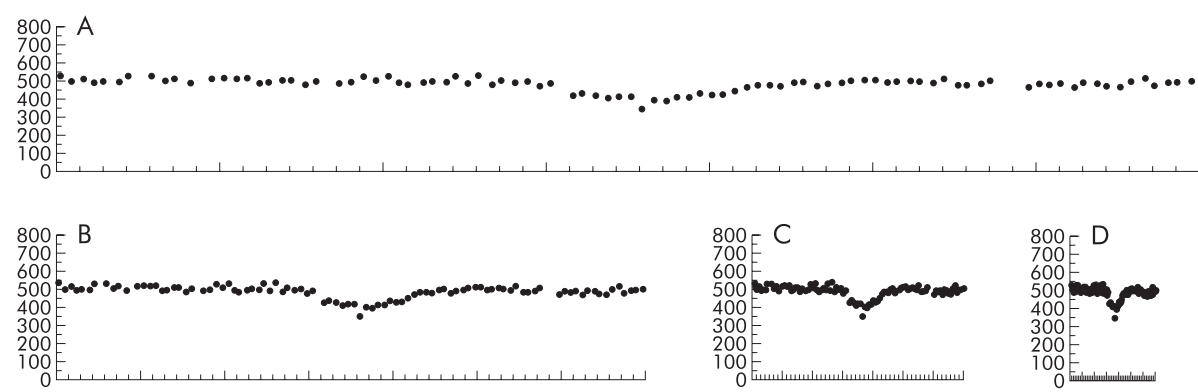

Figure 1 Seven weeks of PEF data, including a viral exacerbation, plotted on (A) Allersearch chart (standardised vertical:horizontal scale 100:382), (B) mini-Wright chart (scale 100:230), (C) prototype chart (scale 100:82), and (D) chart with standard occupational asthma proportions ${ }^{9}$ (scale 100:39). For comparison the charts have been standardised to a vertical range of $0-800 \mathrm{l} / \mathrm{min}$ and gridlines have been omitted. On horizontally expanded charts ( $A$ and $B$ ) the exacerbation onset and resolution are difficult to identify, but on horizontally compressed charts (C and D) the baseline PEF data form a solid "band" from which the onset of the exacerbation stands out clearly.

which may be used in patients with severe asthma or poor perception, would be best displayed with at least 4 weeks per page in order to identify time trends without excessive visual interruption.

\section{NEURAL BASIS FOR THE EFFECT OF CHART SCALE ON APPEARANCE OF EXACERBATIONS}

The qualitative differences in the appearance of PEF data on different charts are consistent with existing knowledge about visual search processes from psychometric and functional neuroimaging studies. ${ }^{19}$ Attentive visual search involves serial focus on individual data points, but it has consistently been found that visual working memory can handle only 3-4 such individual points at once. ${ }^{20}{ }^{21} \mathrm{~A}$ second type of visual search process involves the pre-attentive identification of salient objects. ${ }^{12}$ These may be actual objects or perceived objects created by visual binding of multiple putatively separable data points. ${ }^{19}$ We use this process when we visually integrate the dots of a Neo-Impressionist painting. Pre-attentive object detection is enhanced if the object "pops out" from the background data as an emergent feature, ${ }^{22}$ with "pop out" enhanced by orientation (angle) contrast. Recent functional
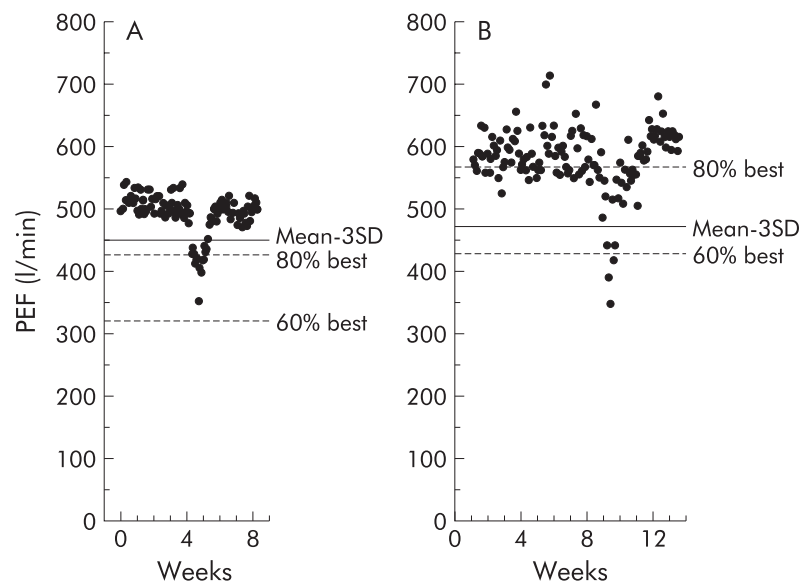

Figure 2 Usefulness of three different PEF threshold values (action points) in detecting a viral asthma exacerbation experienced by two patients with different baseline (pre-exacerbation) PEF variability. For the patient in A with low baseline PEF variability, an action point of $60 \%$ best would have missed the exacerbation whereas, for the patient in $B$ with high baseline PEF variability, an action point of $80 \%$ best would have grossly overdiagnosed exacerbations. For both patients an action point of three standard deviations below the mean would appear to have appropriately detected the exacerbation. See text (right) for a proposed method of estimating this cut off point. neuroimaging studies have localised serial focusing to the primary visual cortex and object perception to the lateral occipital complex, and have shown that visual grouping "frees up" the primary visual cortex for attention to new items. ${ }^{23}$

These concepts can be applied to the observed differences between PEF charts. On horizontally expanded charts (fig 1A and $\mathrm{B}$ ) each PEF is viewed as a separate point and is therefore compared in working visual memory with only a few adjacent values. Visual attention on an expanded chart thus focuses on day to day variation rather than on overall trends. With horizontal compression (fig $\mathrm{IC}$ and D) the baseline PEF data are visually bound to form a solid "band", its thickness reflecting baseline PEF variability and its slope indicating whether PEF is stable or is rising or falling (as illustrated in Mitchell et $a l^{6}$ ). The exacerbation then "pops out" from the background data as a V-shaped object.

Furthermore, if fig $\mathrm{IC}$ and $\mathrm{D}$ are uncovered from left to right as if the PEF data are being viewed prospectively, new PEF data which are similar to previous values appear to be visually added to the existing "band". However, the first low PEF (in this case, four standard deviations below mean) is too far away to be visually bound and is, instead, perceived as a separate, clearly abnormal point. This effect is enhanced by viewing the chart from a distance, suggesting that detection of the exacerbation is not due to examination of fine detail. Thus, importantly, visual recognition of onset of an exacerbation on a compressed chart appears to take into account the patient's existing level of variability.

\section{POTENTIAL IMPLICATIONS FOR CONSTRUCTION OF ASTHMA ACTION PLANS}

In view of the poor performance of percentage based action points in the diagnosis of asthma exacerbations, ${ }^{3}$ as shown in fig 2, it is interesting to speculate about the potential for visual estimation of quality control based action points from a compressed PEF chart. As a rough guide, the "band" of baseline data will include approximately mean $\pm 1.96 \mathrm{SD}$ (95\% confidence range), so a point three standard deviations below the mean-which has high sensitivity and specificity for diagnosis of exacerbations ${ }^{3}$ - should lie below this band by approximately one quarter of the band's width. Such visual estimation of action points would be feasible in clinical practice but would obviously need careful validation, first with visual perception methodology and then with prospective clinical studies.

\section{LIMITATIONS OF MANUAL DATA ENTRY ON COMPRESSED PEF CHARTS}

Electronically entered data can be displayed in any desired format (as with OASYS), but the extent to which the scale of 
paper PEF charts can be horizontally compressed is usually limited by the need for manual data entry, with an attendant burden to patients. ${ }^{24}$ In our experience the practical upper limit for manual entry appears to be approximately 8 weeks per A4 page (for PEF $0-750 \mathrm{l} / \mathrm{min}$, landscape). Simple additional features (such as major/minor gridlines, repeated axis labels) can markedly improve ease of data entry and hence reduce the burden of monitoring for patients.

\section{CONCLUSIONS}

Asthma guidelines highlight the usefulness of PEF monitoring for assessment of asthma severity, monitoring of response to treatment, and detection of exacerbations. However, some clinicians have expressed concerns about the relevance of PEF monitoring, ${ }^{25}{ }^{26}$ particularly because of poor adherence and data falsification. ${ }^{27}$ Lack of standardisation of PEF charts may have contributed to these problems, as indifference or confusion by clinicians in the interpretation of PEF data is readily sensed by patients and is reflected in poor adherence, which further reduces the enthusiasm of the clinician. ${ }^{26}$ At the very least, there is an obvious need for standardisation of PEF charts to avoid confusion for patients and to allow development of pattern recognition skills by clinicians. Our observations suggest that preference should be given to a horizontally compressed chart to facilitate identification of exacerbations and of overall trends, but this hypothesis must be evaluated by retrospective and prospective studies. Ultimately, clinical expertise in PEF pattern recognition may be able to be incorporated into electronic decision making algorithms, as has occurred in occupational asthma. However, in the meantime, the ideal PEF chart will represent a compromise between ease of manual data entry and ease of interpretation. Attention to both of these aspects may improve adherence by reducing the burden of PEF monitoring and increasing its perceived value to both patients and clinicians as part of collaborative asthma self-management.

\section{ACKNOWLEDGEMENTS}

This work was supported by the Asthma Foundation of NSW, the Australian Government, the CRC for Asthma, and Royal Prince Alfred Hospital. The contribution of J Paul Seale in reviewing the manuscript is appreciated.

\section{Authors' affiliations \\ H K Reddel, S D Vincent, Woolcock Institute of Medical Research (Royal Prince Alfred Hospital and University of Sydney), P O Box M77, Camperdown, NSW 2050, Australia \\ J Civitico, Royal Prince Alfred Hospital, Camperdown, NSW 2050, Australia}

The authors have no competing financial or other interests. The prototype PEF chart referred to in the text is distributed free of charge to patients.

\section{REFERENCES}

1 GINA (Global Initiative for Asthma). Workshop Report. Global strategy for asthma management and prevention. NIH Publication No 02-3659, 2002.

2 Gibson PG, Powell H. Written action plans for asthma: an evidence-based review of the key components. Thorax 2004;59:94-9.

3 Gibson PG, Wlodarczyk J, Hensley MJ, et al. Using quality-control analysis of peak expiratory flow recordings to guide therapy for asthma. Ann Intern Med 1995; 123:488-92.

4 Boggs PB, Wheeler D, Washburne WF, et al. Peak expiratory flow rate control chart in asthma care: chart construction and use in asthma care. Ann Allergy Asthma Immunol 1998;81:552-62.

5 Turner-Warwick $M$. On observing patterns of airflow obstruction in chronic asthma. Br J Dis Chest 1977;71:73-86.

6 Mitchell DM, Gildeh P, Dimond AH, et al. Value of serial peak expiratory flow measurements in assessing treatment response in chronic airflow limitation. Thorax 1986;41:606-10.

7 Burge PS, O'Brien IM, Harries MG. Peak flow rate records in the diagnosis of occupational asthma due to colophony. Thorax 1979;34:308-16.

8 Cote J, Kennedy S, Chan-Yeung M. Quantitative versus qualitative analysis of peak expiratory flow in occupational asthma. Thorax 1993;48:48-51.

9 Bright P, Burge PS. Occupational lung disease. 8. The diagnosis of occupational asthma from serial measurements of lung function at and away from work. Thorax 1996;51:857-63.

10 Gannon PF, Newton DT, Belcher J, et al. Development of OASYS-2: a system for the analysis of serial measurement of peak expiratory flow in workers with suspected occupational asthma. Thorax 1996;51:484-9.

11 Meyer J, Shamo MK, Gopher D. Information structure and the relative efficacy of tables and graphs. Human Factors 1999;41:570-87.

12 Grill-Spector K, Kourtzi Z, Kanwisher N. The lateral occipital complex and its role in object recognition. Vision Res 2001;41:1409-22.

13 Tufte ER. The visual display of quantitative information. Cheshire, Connecticut: Graphics Press, 1983.

14 Global Initiative for Asthma. Patient guide - what you and your family can do about asthma. Bethesda, MD: National Institutes of Health, 1995, 30. http:// www.ginasthma.com/PATIENT/patient_guide.pdf (accessed June 2004).

15 British Thoracic Society/Scottish Intercollegiate Guidelines Network. British guideline on the management of asthma, Annex 8, 2003. http://www.britthoracic.org.uk/docs/asthmafull.pdf (accessed April 2004)

16 Asthma UK. Your personal asthma diary and action plan, National Asthma Campaign. http://www.asthma.org.uk/about/pdf/control.pdf (accessed July 2004).

17 Reddel H, Ware S, Marks G, et al. Differences between asthma exacerbations and poor asthma control. Lancet 1999;353:364-9 (erratum in Lancet, 1999;353:758).

18 Johnston SL, Pattemore PK, Sanderson G, et al. Community study of role of viral infections in exacerbations of asthma in 9-11 year old children. BMJ 1995;310:1225-8.

19 Wheeler ME, Treisman AM. Binding in short-term visual memory. J Exp Psychol Gen 2002;131:48-64.

20 Sperling G. The information available in brief visual presentations. Psychol Monogr 1960;74:1-29.

21 Vogel EK, Machizawa MG. Neural activity predicts individual differences in visual working memory capacity. Nature 2004;428:748-51.

22 Greaney J, MacRae AW. Visual search and the detection of abnormal readings in graphical displays. Acta Psychol 1997;95:165-79.

23 Murray SO, Kersten D, Olshausen BA, et al. Shape perception reduces activity in human primary visual cortex. Proc Natl Acad Sci USA 2002;99:15164-9.

24 Reddel HK, Toelle BG, Marks GB, et al. Analysis of adherence to peak flow monitoring when recording of data is electronic. BMJ 2002;324:146-7.

25 Brusasco V. Usefulness of peak expiratory flow measurements: is it just a matter of instrument accuracy? Thorax 2003;58:375-6.

26 Brand PL, Roorda RJ. Usefulness of monitoring lung function in asthma. Arch Dis Child 2003;88:1021-5.

27 Verschelden P, Cartier A, L'Archeveque J, et al. Compliance with and accuracy of daily self-assessment of peak expiratory flows (PEF) in asthmatic subjects over a three month period. Eur Respir J 1996;9:880-5. 